\title{
Morphology of Near- and Semispherical Melted Chips after the Grinding Processes Using Sol-Gel Abrasives Based on SEM-Imaging and Analysis
}

\author{
W. Kapłonek, ${ }^{1}$ K. Nadolny, ${ }^{2}$ and W. Habrat ${ }^{3}$ \\ ${ }^{1}$ Subject Group of Metrology and Quality, Department of Mechanical Engineering, Faculty of Mechanical Engineering, \\ Koszalin University of Technology, Racławicka 15-17, 75-620 Koszalin, Poland \\ ${ }^{2}$ Department of Mechanical Engineering, Faculty of Mechanical Engineering, Koszalin University of Technology, \\ Racławicka 15-17, 75-620 Koszalin, Poland \\ ${ }^{3}$ Department of Manufacturing Techniques and Automation, Faculty of Mechanical Engineering and Aeronautics, \\ Rzeszów University of Technology, Wincentego Pola 2, 35-959 Rzeszów, Poland \\ Correspondence should be addressed to K. Nadolny; krzysztof.nadolny@tu.koszalin.pl
}

Received 31 January 2016; Accepted 12 May 2016

Academic Editor: Michael Aizenshtein

Copyright (C) 2016 W. Kapłonek et al. This is an open access article distributed under the Creative Commons Attribution License, which permits unrestricted use, distribution, and reproduction in any medium, provided the original work is properly cited.

\begin{abstract}
Selected issues related to SEM-imaging and image analysis of spherical melted chips formed during the grinding process are presented and discussed. The general characteristics of this specific group of machining products are given. Chip formation phenomena, as well as their overall morphology, are presented using selected examples of near- and semispherical melted chips occurring singly or concentrated in clusters on the grinding wheel surface after the machining process. Observation of the spherical melted chips and acquisition of their images were carried out for grinding wheel active surfaces with microcrystalline sintered corundum abrasive grains $\mathrm{SG}^{\mathrm{TM}}$ after the internal cylindrical grinding process of a 100Cr6 steel and Titanium Grade $2^{\circledR}$ alloy by use of a scanning electron microscope, JEOL JSM-5500LV. Analysis of the obtained SEM micrographs was carried out by Image-Pro ${ }^{\circledR}$ Plus 5.0 software to determine the selected geometrical parameters describing the morphological features of the assessed chips.
\end{abstract}

\section{Introduction}

Chip morphology has been, for many years, the key factor characterizing machining processes. Many examples of investigations concerning chip morphology in order to obtain new knowledge about basic phenomena in machining processes such as turning $[1,2]$, milling [3-5], drilling [6, 7], and grinding $[8,9]$ may be found in the literature.

One of the most interesting of these processes is abrasive machining, in particular, the grinding process. Both the undefined geometry and the number of abrasive grains involved in the material removal process implicate the high stochastic character of such processes. Analysis of chip form and geometry has given researchers information about chip formation, which is one of the basic phenomena in grinding, often used for characterization of the process conditions and obtained results.
Tso [10] defined six basic types of chips on the example of the surface grinding process of the INCONEL ${ }^{\circledR}$ alloy 718: flowing, shearing, ripping, piece, knife, and melting chips. On the basis of experimental studies, he described the morphology of chips, the share of individual fractions in a group of chips generated in grinding, and the impact of selected parameters of process on the share of individual types of chips. One of the most interesting forms of chips is those which are melted, as they depend directly on thermal conditions in the contact zone between the workpiece and the grinding wheel active surface (GWAS). Wong and Doyle [11] drew attention to the form of chips throughout a sample issue of the impact of a fragmented zone on the rise of metal removal in the form of thin delaminated wear platelets. The authors demonstrated this effect by observing the forms of chips generated in the examined process, stating that thin delaminated wear platelets are evident when grinding in an 


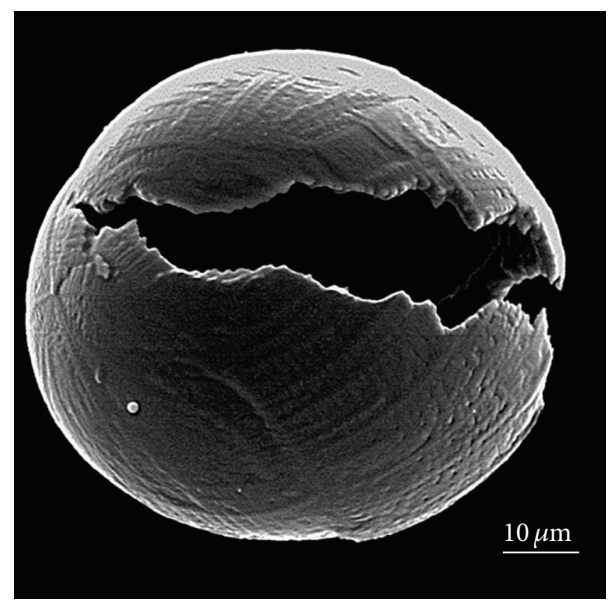

FIGURE 1: SEM micrograph of the grinding debris from AISI 1055 steel showing a hollow spherical particle with a fine dendritic microstructure both outside and inside the sphere [11].

inert atmosphere and take the form of oxide hollow spheres (spherical chips and melted globules) when grinding in air (Figure 1).

Studies of Malkin [12], as well as Doyle and Dean [13], have pointed out that more perfectly formed spherical chips form as a result of grinding debris undergoing surface oxidation in the atmosphere. This is what causes melting of the grinding debris into a sphere (globule). Spherical chips are formed as a result of ignition of the hot smaller chips in air after their formation followed by solidification. Letner [14] has indicated that the spark stream, and hence spherical chips formation, does not occur when the grinding process is conducted in a vacuum or in an inert gas. This further demonstrates the importance of oxygen in the formation of the spheres.

Modern varieties of electron microscopy are particularly useful in the observations and analysis of phenomena related to abrasive machining processes. An interesting review of the capabilities of these techniques in relation to the wide range of results obtained by the use of different variations of grinding processes, as well as the condition of the active surface of the abrasive tools, was presented by Badger in a two-part work $[15,16]$.

Electron microscopy is also invaluable in cases when morphological analysis of selected features characterizing the (near- and semi-) spherical melted chips, occurring singly or concentrated in clusters, is needed as reported by Lu et al. [17] as well as by Su and Liu [18]. In this work, a similar analysis for the above-mentioned chips after the grinding processes, based on SEM-imaging and analysis, was carried out in order to better understand chip formation phenomena when grinding wheels with sol-gel abrasive grains are used.

\section{Materials and Methods}

2.1. Following Steps of the Experimental Investigations. The investigations were divided into the following steps:
TABLE 1: Chemical composition and percentage of elements of $100 \mathrm{Cr} 6$ steel $^{(1)}$.

\begin{tabular}{lcc}
\hline $\begin{array}{l}\text { Chemical } \\
\text { element }\end{array}$ & Percentage of elements, \% & $\begin{array}{c}\text { Permissible deviations of } \\
\text { the product }\end{array}$ \\
\hline $\mathrm{C}$ & $0.93-1.05$ & \pm 0.03 \\
$\mathrm{Si}$ & $0.15-0.35$ & \pm 0.03 \\
$\mathrm{Mn}$ & $0.25-0.45$ & \pm 0.04 \\
$\mathrm{P}$ & 0.025 & +0.005 \\
$\mathrm{~S}$ & 0.015 & +0.005 \\
$\mathrm{Cr}$ & $1.35-1.60$ & \pm 0.05 \\
$\mathrm{Mo}$ & 0.10 & \pm 0.03 \\
$\mathrm{Al}$ & 0.050 & +0.010 \\
$\mathrm{Cu}$ & 0.30 & +0.03 \\
\hline
\end{tabular}

${ }^{(1)}$ Material is produced by Lucefin S.p.A. (Plemo, Italy).

(1) Preparation and abrasive machining of the samples.

(2) Location and observation of the GWAS with spherical melted chips occurring singly or concentrated in clusters.

(3) Selection of the GWAS areas with visible spherical chips and their acquisition using a scanning electron microscope JSM-5500LV produced by JEOL Ltd. (Akishima, Tokyo, Japan).

(4) Processing and analysis of acquired SEM micrographs with their detailed interpretation.

2.2. Sample Material and Processing. For the experimental investigations, a set of nine samples in the form of semifabricated rings made of $100 \mathrm{Cr} 6$ steel (six bearing rings, $d_{w}=$ $40 \mathrm{~mm}, b_{w}=18 \mathrm{~mm}$ ) and Titanium Grade 2 alloy (three rings, $d_{w}=56 \mathrm{~mm}, b_{w}=20 \mathrm{~mm}$ ) were prepared. The general characteristics of both materials, including chemical composition and percentage of elements as well as selected physical and mechanical properties, are given in Tables 1 and 2 (100Cr6 steel) and Tables 3 and 4 (Titanium Grade 2 alloy), respectively.

The machining was carried out by the use of an RUP 28P universal grinding machine produced by Mechanical Works Tarnow SA (Tarnow, Poland) carrying out three kinematic variations of the internal cylindrical grinding process:

(i) Plunge grinding $\left(v_{s}=60 \mathrm{~m} / \mathrm{s}, v_{w}=0.75 \mathrm{~m} / \mathrm{s}, v_{\mathrm{fr}}=\right.$ $\left.0.04 \mathrm{~mm} / \mathrm{s}, a_{e}=0.12 \mathrm{~mm}, Q_{\mathrm{GF}}=3.0 \mathrm{~L} / \mathrm{min}\right)$.

(ii) Reciprocal grinding $\left(v_{s}=60 \mathrm{~m} / \mathrm{s}, v_{w}=0.75 \mathrm{~m} / \mathrm{s}\right.$, $\left.v_{\mathrm{fa}}=20 \mathrm{~mm} / \mathrm{s}, a_{e}=0.20 \mathrm{~mm}, Q_{\mathrm{GF}}=3.0 \mathrm{~L} / \mathrm{min}\right)$.

(iii) Traverse grinding $\left(v_{s}=60 \mathrm{~m} / \mathrm{s}, v_{w}=0.75 \mathrm{~m} / \mathrm{s}, v_{\mathrm{fa}}=\right.$ $\left.2.0 \mathrm{~mm} / \mathrm{s}, a_{e}=0.20 \mathrm{~mm}, Q_{\mathrm{GF}}=3.0 \mathrm{~L} / \mathrm{min}\right)$.

In the first type of process, rings made from a 100Cr6 steel and Titanium Grade 2 alloy were used, while, in the rest of investigated grinding processes, only $100 \mathrm{Cr} 6$ steel was used. Different kinematic variations of the same machining process (internal cylindrical grinding) were taken into consideration for evaluating the influence of the process kinematic 
TABLE 2: Selected physical and mechanical properties of 100Cr6 steel.

\begin{tabular}{|c|c|c|c|}
\hline Group of prosperities & Property & Unit & Value \\
\hline \multirow{6}{*}{ Physical } & Poisson number & $v$ & $0.30^{(2)}$ \\
\hline & Specific heat & $\mathrm{J} \cdot \mathrm{kg}^{-1} \cdot \mathrm{K}^{-1}$ & $475^{(1)}$ \\
\hline & Density & $\mathrm{kg} \cdot \mathrm{dm}^{-3}$ & 7.81 \\
\hline & Thermal conductivity & $\mathrm{W} \cdot \mathrm{m}^{-1} \cdot \mathrm{K}^{-1}$ & 46.6 \\
\hline & Electrical resistivity & $\Omega \cdot \mathrm{mm}^{2} \cdot \mathrm{m}^{-1}$ & 0.22 \\
\hline & Electrical conductivity & $\mathrm{S} \cdot \mathrm{mm}^{2} \cdot \mathrm{m}^{-1}$ & 4.55 \\
\hline \multirow{5}{*}{ Mechanical } & Thermal expansion & $10^{-6} \cdot \mathrm{K}^{-1}$ & $11.4^{(1)}$ \\
\hline & \multirow{2}{*}{ Modulus of elasticity } & longitudinal GPa & $210^{(2)}$ \\
\hline & & tangential GPa & $80^{(2)}$ \\
\hline & Bulk modulus & $\mathrm{GPa}$ & $140^{(2)}$ \\
\hline & Poisson number & $v$ & $0.30^{(2)}$ \\
\hline
\end{tabular}

${ }^{(1)}$ Value calculated for the temperature $20-100^{\circ} \mathrm{C}$.

${ }^{(2)}$ Value calculated for the temperature of $20^{\circ} \mathrm{C}$.

TABle 3: Chemical composition and percentage of elements of Titanium Grade ${ }^{\circledR} 2$ alloy ${ }^{(1)}$.

\begin{tabular}{lc}
\hline $\begin{array}{l}\text { Chemical } \\
\text { element }\end{array}$ & $\begin{array}{c}\text { Percentage of elements, } \\
\%\end{array}$ \\
\hline $\mathrm{Ti}$ & Balance \\
$\mathrm{Fe}$ & 0.06 \\
$\mathrm{~N}$ & 0.009 \\
$\mathrm{O}$ & 0.09 \\
$\mathrm{H}$ & 0.006 \\
$\mathrm{C}$ & 0.02 \\
\hline${ }^{(1)}$ Material is produced by Shanghai HeHe International Trading CO., LTD \\
(Shanghai, China) and distributed by Bibus Metals (Fehraltorf, Switzerland).
\end{tabular}

TABLE 4: Selected physical and mechanical properties of Titanium Grade ${ }^{\circledR}$ alloy.

\begin{tabular}{|c|c|c|c|}
\hline Group of prosperities & Property & Unit & Value \\
\hline \multirow{4}{*}{ Physical } & Density & $\mathrm{g} \cdot \mathrm{cm}^{3}$ & 4.51 \\
\hline & $\begin{array}{c}\text { Thermal } \\
\text { conductivity }\end{array}$ & $\mathrm{W} / \mathrm{mK}$ & $20.8^{(1)} / 15^{(2)}$ \\
\hline & Specific heat & $\mathrm{J} \cdot \mathrm{kg}^{-1} \cdot \mathrm{K}^{-1}$ & $520^{(1)} / 600^{(2)}$ \\
\hline & $\begin{array}{l}\text { Electrical } \\
\text { resistivity }\end{array}$ & $\mu \mathrm{W} \cdot \mathrm{cm}$ & $56^{(2)}$ \\
\hline \multirow{5}{*}{ Mechanical } & Yield strength & $\mathrm{MPa}$ & 390 \\
\hline & Tensile strength & $\mathrm{MPa}$ & 495 \\
\hline & $\begin{array}{l}\text { Modulus of } \\
\text { elasticity }\end{array}$ & $\mathrm{GPa}$ & 103 \\
\hline & Elongation & $\%$ & 28 \\
\hline & Hardness & $\mathrm{HV}$ & $160-200$ \\
\hline
\end{tabular}

conditions on the semispherical melted chips formation phenomena.

Machining was conducted with grinding wheel $(1-35 \times$ $20 \times 10-$ SG/F46K7VTO) made of microcrystalline sintered corundum abrasive grains SG produced by Norton (SaintGobain HPM Polska Sp. z o.o., Koło, Poland) and a vitrified bond.

2.3. Acquisition of the SEM Micrographs. The wide range of activities related to the location and observation of those areas of the GWAS, which were interesting due to the possibilities of carrying out a morphological analysis of spherical melted chips, was performed by the use of a scanning electron microscope JSM-5500LV produced by JEOL. A detailed description of this type of microscope is given in $[19,20]$. During acquisition of the SEM micrographs (resolution 1280 $\times 960$ pixels, 8-bit color depth, greyscale mode, and saving format ${ }^{*}$.bmp), three types of magnification ranges were used generally:

(1) Low mag. range $(50 \times-200 \times)$, for general presentation of areas of the GWAS for subsequent more detailed analysis.

(2) Middle mag. range (to $500 \times$ ), for presentation of an area of the GWAS in a wider (panoramic) view.

(3) High mag. range $(1000 \times-4000 \times)$, for presentation of areas of interest (AOI) of the GWAS in a detailed view.

Depending on the magnification, an accelerating voltage in a range of $10-20 \mathrm{kV}$ and a vacuum pressure in a range of 9-11 $\mathrm{Pa}$ were used.

2.4. Processing and Analysis of the SEM Micrographs. All acquired images were processed and analyzed by the use of Image-Pro Plus 5.0 software produced by Media Cybernetics, Inc. (Rockville, MD, USA) - complete scientific software intended for a wide spectrum of activities related to the broadly understood processes of processing and image analysis. In this case, the use of the software boiled down to the following:

(1) Determination of the parameters that may be useful in morphological analysis of selected features characterizing spherical melted chips: from the available 
TABLE 5: Selected geometrical parameters available in Image Pro ${ }^{\circledR}$-Plus 5.1 software, used during morphological analysis of selected features characterizing spherical melted chips.

\begin{tabular}{|c|c|c|c|c|c|}
\hline \multirow{2}{*}{\multicolumn{2}{|c|}{ Parameter }} & \multirow{2}{*}{ Designation } & \multicolumn{2}{|c|}{ Unit } & \multirow{2}{*}{ Description } \\
\hline & & & IPP & SI & \\
\hline \multicolumn{2}{|c|}{ Area } & $A_{n}$ & pixel & $\mu \mathrm{m}^{2}$ & Reports the area of each object (minus any holes). \\
\hline \multicolumn{2}{|c|}{ Perimeter } & $L$ & pixel & $\mu \mathrm{m}$ & $\begin{array}{l}\text { Measurement to report the length of the outline of each } \\
\text { object using a polygonal outline. }\end{array}$ \\
\hline \multicolumn{2}{|c|}{ Fractal dimension } & $D$ & - & - & Reports the fractal dimension of the object's outline. \\
\hline \multirow{2}{*}{ Size } & length & $S_{1}$ & pixel & $\mu \mathrm{m}$ & \multirow{2}{*}{$\begin{array}{l}\text { Reports the caliper length along a major/minor axis of } \\
\text { the object. }\end{array}$} \\
\hline & width & $S_{2}$ & pixel & $\mu \mathrm{m}$ & \\
\hline \multirow{2}{*}{ Diameter } & $\min$. & $S_{\min .}$ & pixel & $\mu \mathrm{m}$ & \multirow{2}{*}{$\begin{array}{l}\text { Reports the length of the shortest/longest line joining } \\
\text { two outline points and passing through the centroid. }\end{array}$} \\
\hline & $\max$ & $S_{\text {max. }}$ & pixel & $\mu \mathrm{m}$ & \\
\hline \multirow{2}{*}{ Feret } & $\min$. & $F_{\min }$ & pixel & $\mu \mathrm{m}$ & \multirow{2}{*}{ Reports the longest/average caliper (Feret) length. } \\
\hline & $\max$. & $F_{\text {max. }}$ & pixel & $\mu \mathrm{m}$ & \\
\hline \multirow{2}{*}{ Radius } & $\min$. & $R_{\min }$ & pixel & $\mu \mathrm{m}$ & \multirow{2}{*}{$\begin{array}{l}\text { Minimum/Maximum distance between object's } \\
\text { centroid and outline. }\end{array}$} \\
\hline & $\max$. & $R_{\text {max. }}$ & pixel & $\mu \mathrm{m}$ & \\
\hline \multicolumn{2}{|c|}{ Roundness } & $R_{S}$ & - & - & $\begin{array}{l}\text { Reports the roundness of each object. Circular objects } \\
\text { will have a } R_{S}=1 \text {; other shapes will have a roundness } \\
\qquad R_{S}>1^{(1)}\end{array}$ \\
\hline
\end{tabular}

parameters in the software (more than fifty), only eight geometrical parameters were selected for analysis. Their general description is given in Table 5.

(2) Carrying out a quantitative analysis of objects in the acquired images: this type of analysis was particularly useful for the assessment of clusters of spherical melted chips.

\section{Results and Discussion}

Microscopic observation of the GWAS $1-35 \times 20 \times 10$ SG/F46K7VTO after internal cylindrical grinding discloses a number of specific products of machining processes in the form of random-kind chips. Even at relatively low magnification and wide field of view, their type and quantity can be identified. Changing the magnification allows one to detect relatively small, in relation to the typical knifeor flowing-type chips, spherical melted chips (Figures 2-6). They can occur alone (a single chip) surrounded by other types of chips or in clusters containing from a few to several dozen chips. An example of a single near-spherical melted chip $\left(R_{S}=1.07\right)$ formed after the internal cylindrical plunge grinding of $100 \mathrm{Cr} 6$ steel is spherical melted chip on the side plane of the abrasive grain made of microcrystalline sintered corundum (Figure 2(a)). From Figure 2(a), an AOI (area of interest) was extracted (size: $25.34 \times 25.08 \mu \mathrm{m}$, mag. $3000 \times$ ), which allowed for the accurate presentation of the general morphology of the near-spherical melted chip and determination of dimensions characterizing presented in Figure 2. Indeed, the observation of a fragment of the GWAS 1-35 × $20 \times 10-$ SG/F46K7VTO (size: $388.88 \times$ $297.77 \mu \mathrm{m}$, mag. $500 \times$ ) revealed the existence of a single near-its geometry (Figure 2(b)). The chip structure observed at relatively high magnification has a clearly visible platelet character. The plates of various shapes and sizes are closely bonded together, forming a strong spherical structure. The main geometrical parameters of this chip are as follows: area: 527.597 $\mu \mathrm{m}^{2}$, perimeter: $73.179 \mu \mathrm{m}$, fractal dimension: 1.014, size (length): $22.993 \mu \mathrm{m}$, size (width): $22.946 \mu \mathrm{m}$, diameter (min.): $23.194 \mu \mathrm{m}$, diameter (max.): $22.318 \mu \mathrm{m}$, Feret (min.): $22.345 \mu \mathrm{m}$, Feret (max.): $23.214 \mu \mathrm{m}$, radius (max.): $11.790 \mu \mathrm{m}$, and radius (min.): $11.018 \mu \mathrm{m}$.

In order to conduct a more comprehensive geometrical analysis of the specific structure of the chip from its central part, an AOI (size: $22.28 \times 7.75 \mu \mathrm{m}$, mag. $5500 \times$ ) was extracted (Figure 2(c)). This AOI was additionally subjected to filtration process to increase the sharpness and contrast of the image (Figure 2(d)). In this case, a high-pass filter (settings: width, 27; height, 25; strength, 2; passes: 1) from module Large Spectral Filters (Image-Pro Plus 5.0) was used. The measurements of the plates show that their length is an average of $1 \mu \mathrm{m}$ to $>3 \mu \mathrm{m}$.

Figure 3 presents a sequence of SEM micrographs (size: $1785 \times 1586.66 \mu \mathrm{m}$, mag. $50 \times)$ with visible extensive clogged areas on the GWAS $1-35 \times 20 \times 10$-SG/F46K7VTO impregnated by sulphur generated after the internal cylindrical plunge grinding of the Titanium Grade 2 alloy. In the central part of the extracted AOI from Figure 3(a) (size: $400 \times$ $288.33 \mu \mathrm{m}$, mag. $200 \times$ ), a couple of near-spherical melted chips $\left(1-R_{S}=1.17,2-R_{S}=1.34\right)$ were clearly observed (Figure 3(b)). The chips were located in the trough on the border of two clogged areas of the workpiece material. A detailed view of this situation is presented in Figure 3(c). Both single and near-spherical melted chips were measured (the values of the selected geometrical parameters are given in Figure 3(d)) and compared with the dimensions of random-kind chips in the close neighborhood. The comparison (Figure 3(d)) 


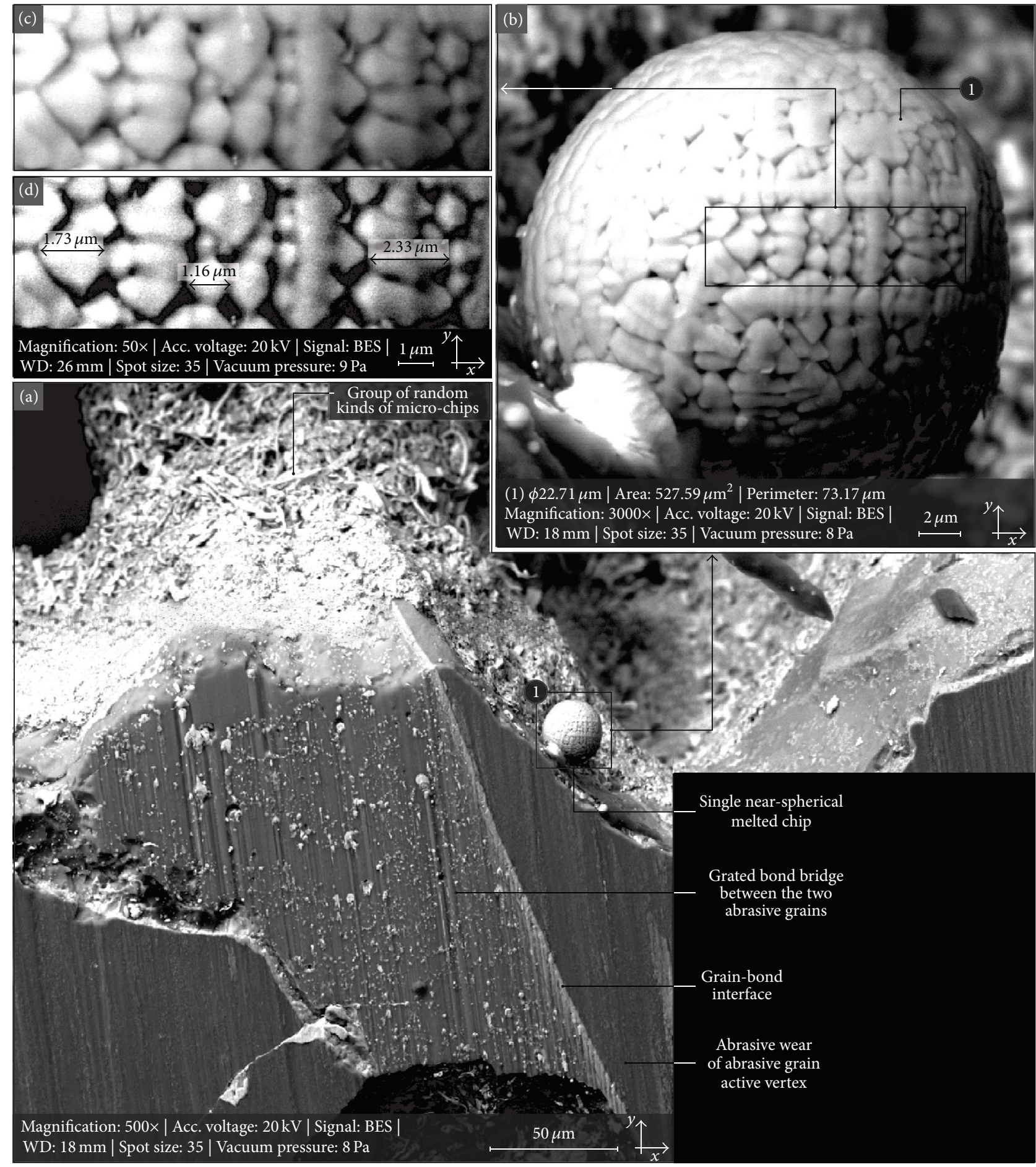

FIGURE 2: General morphology of near-spherical melted chip formed after internal cylindrical plunge grinding of 100Cr6 steel obtained by use of scanning electron microscope, JSM-550LV, produced by JEOL: (a) SEM micrograph (size: $388.88 \times 297.77 \mu \mathrm{m}$, mag. 500×) of GWAS 1-35× $20 \times 10$-SG/F46K7VTO with centrally positioned single near-spherical melted chip, (b) AOI (size: $25.34 \times 25.08 \mu \mathrm{m}$, mag. $3000 \times$ ) extracted from (a) with calculated basic dimensions of chip, (c) AOI (size: $12.13 \times 3.87 \mu \mathrm{m}$, mag. $5500 \times$ ) extracted from (b) with visible structure of chip, and (d) image from (c) after use of filtering process (high-pass filter). Note: Acc. voltage, accelerating voltage; BES, backscattered electron (shadow image); WD, working distance. 



FIGURE 3: General morphology of near-spherical melted chips formed after internal cylindrical plunge grinding of Titanium Grade 2 alloy obtained by use of scanning electron microscope JSM-550LV produced by JEOL: (a) SEM micrograph (size: $1785 \times 1586.66 \mu \mathrm{m}$, mag. $50 \times$ ) of GWAS 1-35 × $20 \times 10$-SG/F46K7VTO impregnated by sulphur with two vast clogged areas, (b) AOI (size: $400 \times 288.33 \mu \mathrm{m}$, mag. $200 \times$ ) extracted from (a), (c) AOI (size: $181.50 \times 171.00 \mu \mathrm{m}$, mag. $500 \times$ ) extracted from (b) with couple of clearly visible single near-spherical melted chips in central part of image, and (d) AOI (size: $80.78 \times 58.23 \mu \mathrm{m}$, mag. $2000 \times$ ) extracted from (c) with calculated basic dimensions of chips. Note: Acc. voltage, accelerating voltage; BES, backscattered electron (shadow image); WD, working distance. 


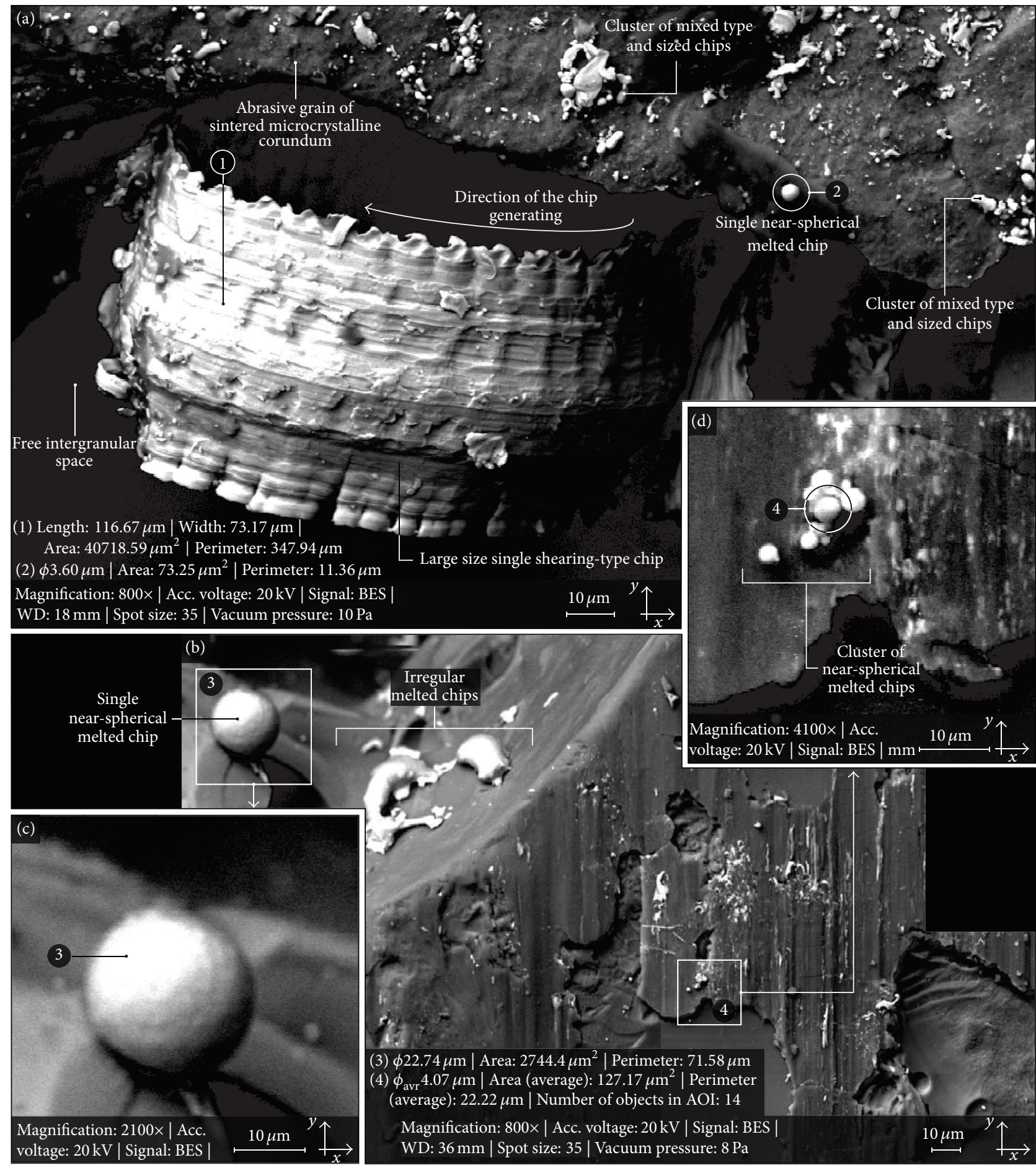

FIGURE 4: General morphology of single near-spherical melted chips formed after internal cylindrical reciprocal grinding of 100Cr6 steel obtained by use of scanning electron microscope JSM-550LV produced by JEOL: (a) SEM micrograph (size: $209.52 \times 128.57 \mu \mathrm{m}$, mag. $800 \times$ ) of GWAS 1-35 × $20 \times 10$-SG/F46K7VTO, showing size comparison between large size single shearing-type chip and typical single nearspherical melted chip, (b) SEM micrograph (size: $293 \times 180 \mu \mathrm{m}$, mag. 500×) of GWAS 1-35 × 20×10-SG/F46K7VTO, showing the situation, when, on this same GWAS, single near-spherical melted chip and cluster of near-spherical melted chips were formed, (c) AOI (size: $48.38 \times$ $48.38 \mu \mathrm{m}$, mag. $2100 \times$ ) extracted from (b) with single near-spherical melted chip, and (d) AOI (size: $48.38 \times 48.38 \mu \mathrm{m}$, mag. $4200 \times$ ) extracted from (b) with cluster of near-spherical melted chips. Note: Acc. voltage, accelerating voltage; BES, backscattered electron (shadow image); $\mathrm{WD}$, working distance. 


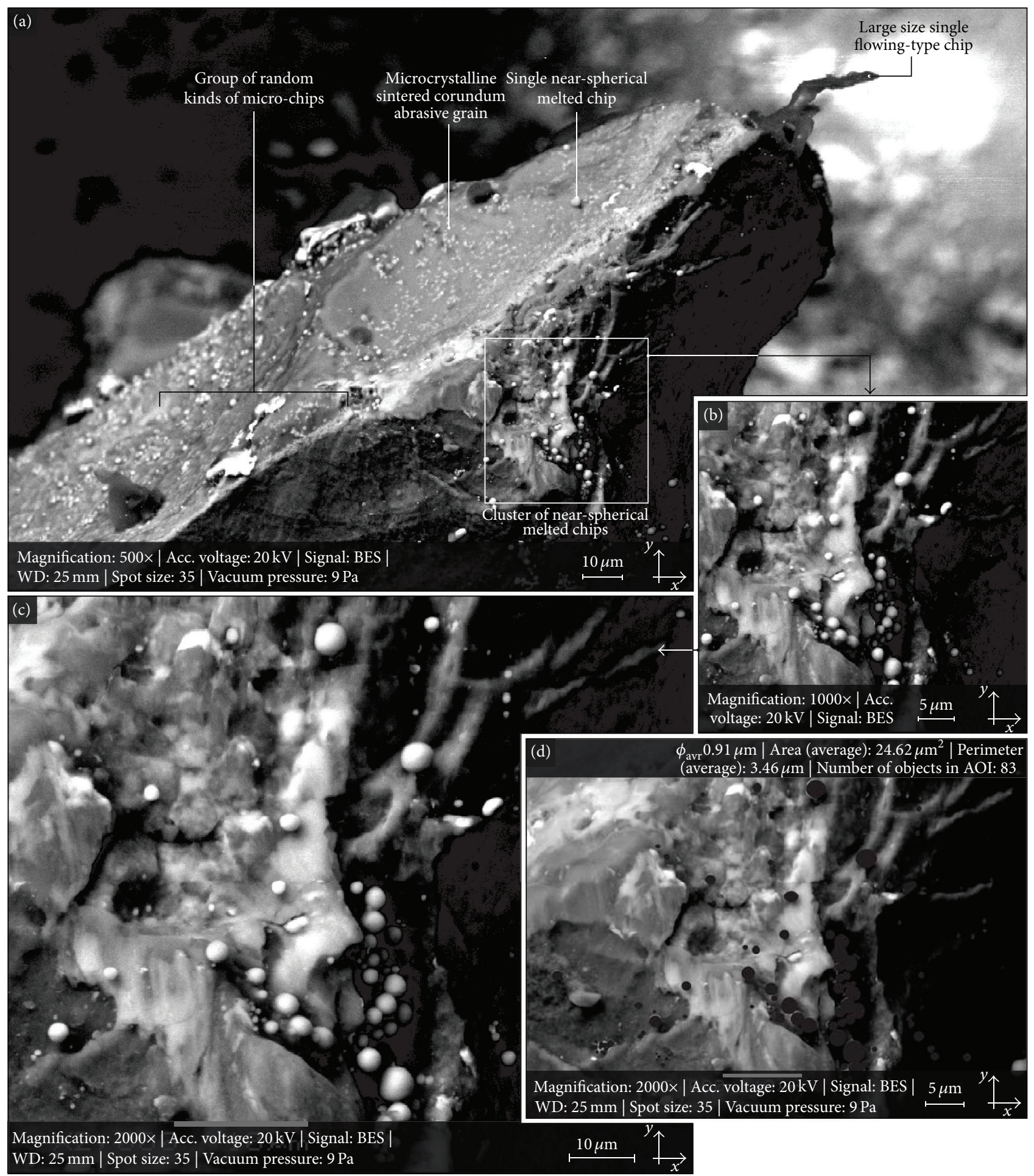

FIGURE 5: General morphology of cluster of near-spherical melted chips formed after internal cylindrical traverse grinding of $100 \mathrm{Cr} 6$ steel alloy obtained by use of scanning electron microscope JSM-550LV produced by JEOL: (a) SEM micrograph (size: $251.42 \times 142.85 \mu \mathrm{m}$, mag. $500 \times$ ) of GWAS 1-35 × $20 \times 10$-SG/F46K7VTO, showing area of concentration (cluster) of single near-spherical melted chips, (b) AOI (size: $41.42 \times 41.42 \mu \mathrm{m}$, mag. $1000 \times$ ) extracted from (a), (c) AOI (size: $101.89 \times 85.25 \mu \mathrm{m}$, mag. $2000 \times$ ) extracted from (b), and (d) SEM micrograph prepared for quantitative analysis in Image-Pro Plus 5.0 software. Note: Acc. voltage, accelerating voltage; BES, backscattered electron (shadow image); WD, working distance. 


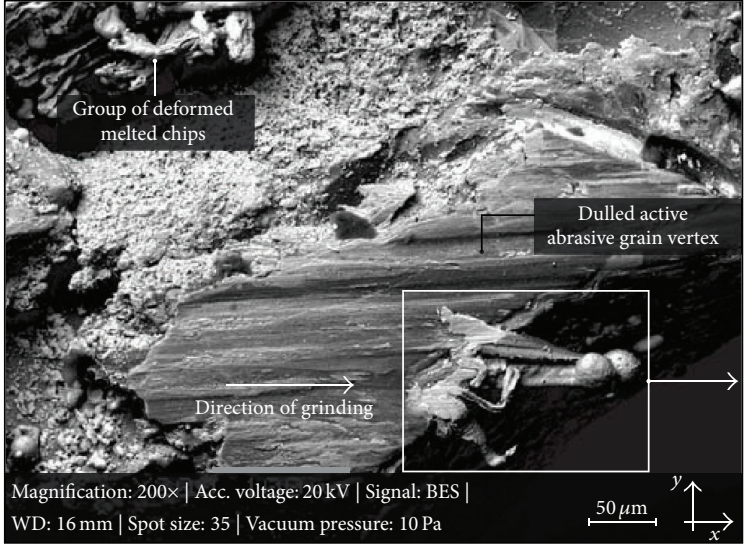

(a)

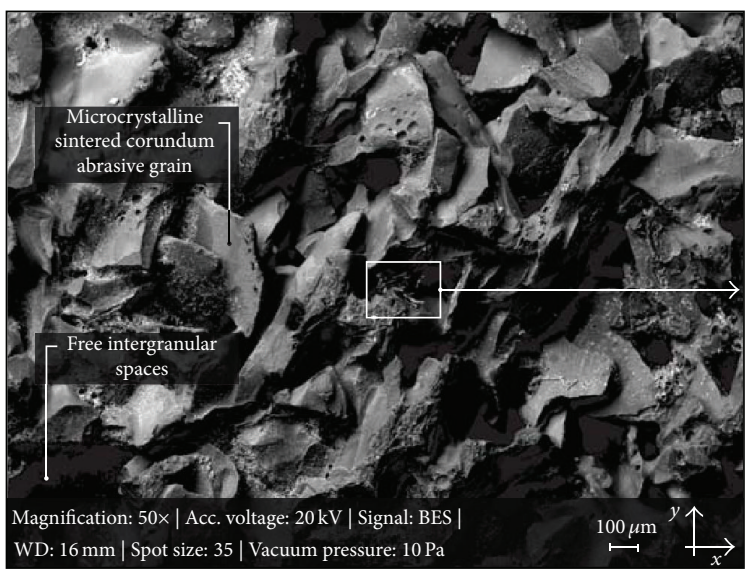

(c)

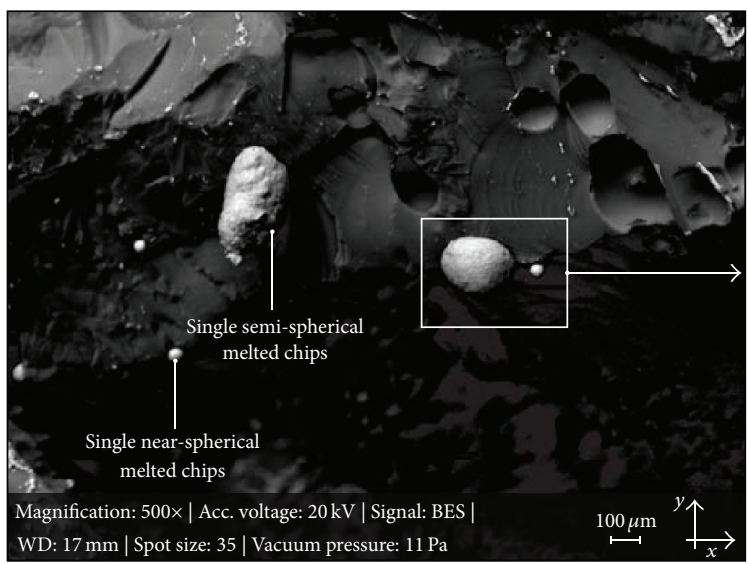

(e)

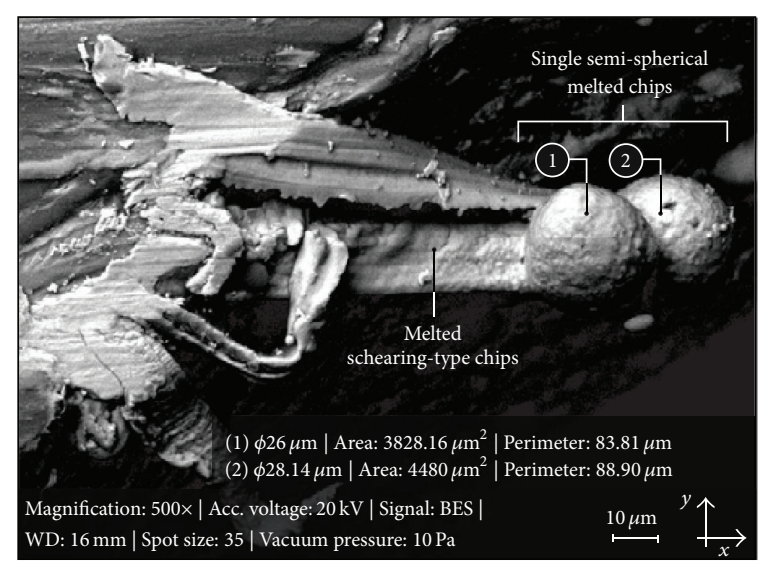

(b)

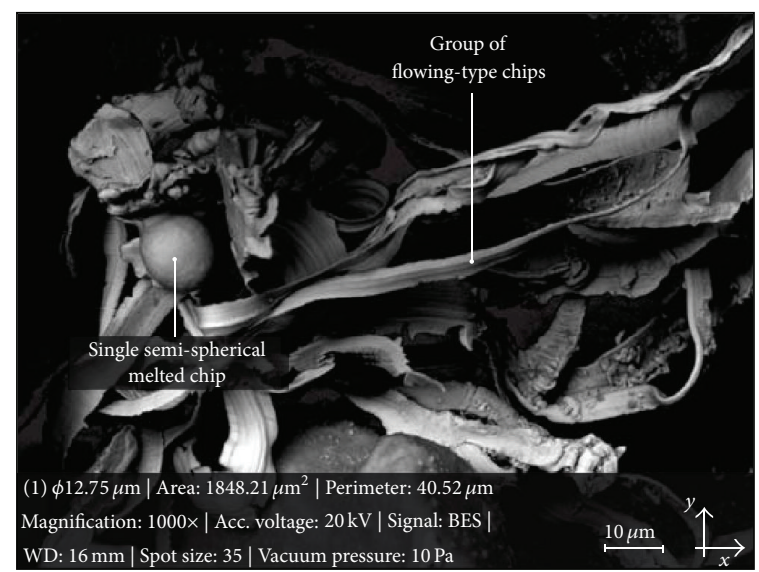

(d)

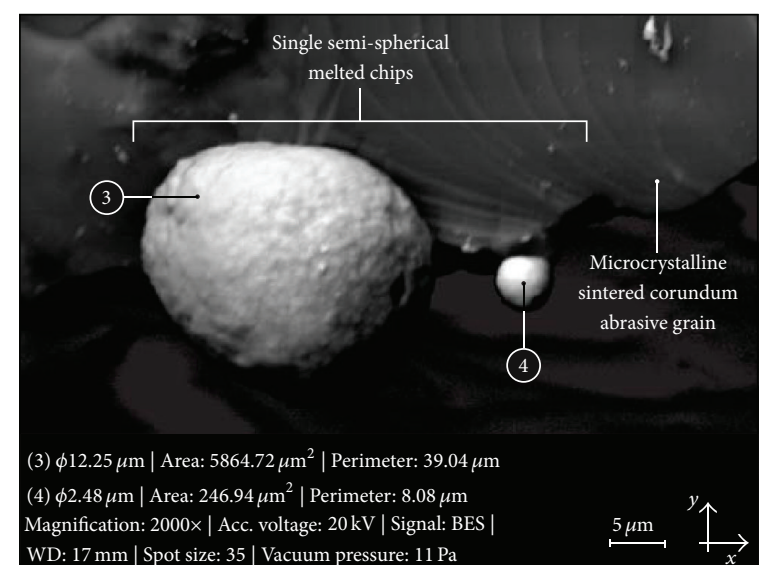

(f)

FIGURE 6: General morphology of semispherical melted chips formed after internal cylindrical grinding (carried out in various kinematic variations) of 100 Cr6 steel obtained by use of scanning electron microscope JSM-550LV produced by JEOL: (a) SEM micrograph (size: 543.20 $\times 403.08 \mu \mathrm{m}$, mag. $200 \times$ ) of GWAS 1-35 $\times 20 \times 10$-SG/F46K7VTO after internal cylindrical traverse grinding of 100Cr6 steel, showing two forms of spherical melted chips which formed and bonded with dulled abrasive grain vortex, (b) AOI (size: $170.37 \times 12.30 \mu \mathrm{m}$, mag. $500 \times$ ) extracted from (a), (c) SEM micrograph (size: $2514.28 \times 1917.14 \mu \mathrm{m}$, mag. 500×) of the GWAS 1-35 × $20 \times 10-$ SG/F46K7VTO after internal cylindrical plunge grinding of 100Cr6 steel, showing concentration of random-kind chips in free intergranular space between SG abrasive grains, (d) AOI (size: $222.85 \times 165.71 \mu \mathrm{m}$, mag. 1000×) extracted from (c), (e) SEM micrograph (size: $258.82 \times 194.41 \mu \mathrm{m}$, mag. 500×) of the GWAS 1-35 × $20 \times 10$-SG/F46K7VTO after internal cylindrical plunge grinding of 100Cr6 steel, showing various sizes of single semispherical melted chips on SG abrasive grain, and (f) AOI (size: $53.52 \times 39.70 \mu \mathrm{m}$, mag. $2000 \times$ ) extracted from (e). Note: Acc. voltage, accelerating voltage; BES, backscattered electron (shadow image); WD, working distance. 
shows that the dimensions of knife- and slice-type chips $(80.78 \times 58.23 \mu \mathrm{m}$, mag. $2000 \times)$ recognized in the AOI are, on average, four times smaller than near-spherical melted chips (the criteria were the $A_{n}$ and $S_{\text {max. }}$ parameter values).

The comparison of the morphology of near-spherical melted chips and other types of chips, formed after internal cylindrical plunge grinding of 100Cr6 steel, is presented in Figure 4(a). In this case, on the selected AOI (size: 209.52 $\times 128.57 \mu \mathrm{m}$, mag. $800 \times$ ), the comparison is related to large size shearing-type chip. The values of the selected geometrical parameters calculated for two types of chips (Image-Pro Plus 5.0 software) are given on the left-hand side of Figure 4(a). A visual analysis of both of them will give one the opportunity to compare their different structures and dimensions (given by $S_{1}, S_{2}, A_{n}$, and $L$ parameter values).

In presenting an analyzed AOI (size: $293 \times 180 \mu \mathrm{m}$, mag. $500 \times$ ) of a GWAS, Figure 4(b) shows that chips of the same type may occur singly (Figure $4(\mathrm{c})$ ) or in clusters comprising from several chips to over a dozen (Figure $4(\mathrm{~d})$ ). The results of a dimensional analysis of the chips in the above-described situation are given in Figure 4(b).

In many cases, for clusters of near-spherical melted chips, the carrying out of a quantitative analysis is essential. In Figure 5(a), the SEM micrograph (size: $251.42 \times 142.85 \mu \mathrm{m}$, mag. $500 \times)$ of a fragment of the GWAS $1-35 \times 20 \times 10-$ SG/F46K7VTO after the internal cylindrical traverse grinding of $100 \mathrm{Cr} 6$ steel is presented. In the central part of this SEM micrograph, the SG abrasive grain and random kind of the chips, from the flowing to the near-spherical melted type, are clearly visible. Figure 5(a) is a good starting point for visually locating the concentration of small size near-spherical melted chips. Such a concentration was found on the side plane of an SG abrasive grain (Figure 5(b)). In order to carry out a quantitative analysis from Figure 5(b), an AOI (size: 101.89 $\times 85.25 \mu \mathrm{m}$, mag. $2000 \times$ ) was extracted, which is presented in Figure 5(c). Moreover, an image intended for this analysis was processed in an appropriate way to generate the map of the objects (black points) that were counted (Figure 5(d)) in automatic mode in the Count/Size module of the ImagePro Plus 5.0 software. In addition, the carried out procedure allowed one to calculate the values of selected geometrical parameters. The $S_{\text {max. }}, A_{n}$, and $L$ parameter values are given in Figure 5(d).

If near-spherical melted chips are not fully formed, they can take the form of semispherical chips. These forms in few morphological variants are presented in Figure 6. Each variant of the semispherical chip is shown in a relatively large range of magnification (500-2000×) for more comprehensive observation of their morphological characteristics. A dimensional analysis for defining the basic geometrical parameters was also carried out.

A SEM micrograph (size: $543.20 \times 403.08 \mu \mathrm{m}$, mag. $200 \times$ ) of the GWAS 1-35 × $20 \times 10$-SG/F46K7VTO after the internal cylindrical traverse grinding of $100 \mathrm{Cr} 6$ steel is shown in Figure 6(a). This figure presents a quite interesting situation when (under a high temperature) the two various forms of melted chips were formed and bonded with a dulled abrasive grain vortex. The direction of the chips forming was convergent with the direction of the grinding process.
Extracted from Figure 6(a), an AOI (size: $170.37 \times 12.30 \mu \mathrm{m}$, mag. $500 \times$ ) shows the melted shearing-type chips with two single semispherical chips formed on their ends $\left(1-R_{S}=\right.$ $\left.1.52,2-R_{S}=1.67\right)$. The $S_{\text {max. }}, A_{n}$, and $L$ parameter values are given (Figure 6(b)). A SEM micrograph (size: 2514.28 $\times 1917.14 \mu \mathrm{m}$, mag. $500 \times)$ of the GWAS $1-35 \times 20 \times 10-$ SG/F46K7VTO after the internal cylindrical plunge grinding of $100 \mathrm{Cr} 6$ steel presents a concentration of random-kind chips in a free intergranular space between SG abrasive grains (Figure 6(c)). Extracted from Figure 6(c), an AOI (size: 222.85 $\times 165.71 \mu \mathrm{m}$, mag. $1000 \times)$ shows a single semispherical chip $\left(R_{S}=1.61\right)$ surrounded by numerous flowing-type chips. This interesting example can be useful in order to compare the morphology of various types of chips. As mentioned previously, the values of selected geometrical parameters related to spherical melted chips are also given (Figure 6(d)).

A SEM micrograph (size: $258.82 \times 194.41 \mu \mathrm{m}$, mag. $500 \times$ ) of the GWAS 1-35 × $20 \times 10$-SG/F46K7VTO after the internal cylindrical plunge grinding of $100 \mathrm{Cr} 6$ steel is shown in Figure 6(e). In the center of this micrograph, the various sizes of single semispherical melted chips on the SG abrasive grain are clearly visible. Two of them were extracted from Figure 6(e) as an AOI (size: $53.52 \times 39.70 \mu \mathrm{m}$, mag. $2000 \times)$ and are presented in Figure 6(f). For these two semispherical melted chips $\left(3-R_{S}=1.83,4-R_{S}=1.57\right)$, the selected geometrical parameters were calculated and are given in Figure 6(f).

A summary of the above-described selected results of these experimental investigations is outlined in Table 6, presenting the average values of selected geometrical parameters calculated for two forms of spherical melted chips formed during the internal cylindrical grinding process and carried out in three kinematic variations.

\section{Conclusions}

In this paper, selected issues have been presented and discussed regarding SEM-imaging and image analysis of spherical melted chips formed on the GWAS $1-35 \times 20 \times$ 10 -SG/F46K7VTO made of SG abrasive grains during the internal cylindrical grinding process (carried out with three kinematic variations). The analyses carried out regarding spherical melted chip formation phenomena and their general morphology enabled the following detailed conclusions to be drawn:

(i) Spherical melted chips are generally represented by two morphological forms: semi- and near-spherical. High magnification of some spherical melted chips allows one to observe their platelet structure (Figure 6(b)). The length of the plates measured from SEM micrographs was in a range from $1 \mu \mathrm{m}$ to $>3 \mu \mathrm{m}$.

(ii) For determination of the above-mentioned forms of the chip, the $R_{S}$ parameter is very useful. Their average value for the analyzed chips (regardless of the kinematic variety of internal cylindrical grinding process and workpiece material) was $R_{S}=1.17$ for near-spherical chips and $R_{S}=1.59$ for semispherical chips. 
TABLE 6: Average values of selected geometrical parameters calculated for two forms of spherical melted chips formed during internal cylindrical grinding process carried out in three kinematic variations.

\begin{tabular}{|c|c|c|c|c|c|c|c|c|c|}
\hline \multirow{4}{*}{$\begin{array}{l}\text { Kinematic variant } \\
\text { of internal } \\
\text { cylindrical } \\
\text { grinding }\end{array}$} & \multirow{4}{*}{$\begin{array}{l}\text { Material } \\
\text { of sample }\end{array}$} & \multicolumn{8}{|c|}{ Form of spherical melted chip } \\
\hline & & \multicolumn{4}{|c|}{ Near-spherical } & \multicolumn{3}{|c|}{ Semi-spherical } & \multirow[b]{3}{*}{$\begin{array}{c}L, \\
\mu \mathrm{m}\end{array}$} \\
\hline & & \multirow[b]{2}{*}{$\begin{array}{l}R_{S} \\
-\end{array}$} & & \multicolumn{5}{|c|}{ Average values of selected geometrical parameters } & \\
\hline & & & $\begin{array}{c}S_{\text {max. }}, \\
\mu \mathrm{m}\end{array}$ & $\begin{array}{l}A_{n} \\
\mu \mathrm{m}^{2}\end{array}$ & $\begin{array}{c}L \\
\mu \mathrm{m}\end{array}$ & $\begin{array}{l}R_{S} \\
-\end{array}$ & $\begin{array}{c}S_{\max } \\
\mu \mathrm{m}\end{array}$ & $\begin{array}{l}A_{n} \\
\mu \mathrm{m}^{2}\end{array}$ & \\
\hline \multirow{2}{*}{$\begin{array}{l}\text { Plunge } \\
\text { grinding }\end{array}$} & $\begin{array}{l}\text { 100Cr6 } \\
\text { steel }^{(1)}\end{array}$ & 1.09 & 19.72 & 503.46 & 37.81 & 1.69 & 25.32 & 1936.84 & 81.92 \\
\hline & 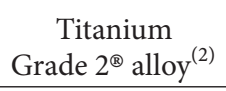 & 1.14 & 17.94 & 491.89 & 33.93 & 1.45 & 23.09 & 1898.11 & 80.14 \\
\hline \multirow{2}{*}{$\begin{array}{l}\text { Reciprocal } \\
\text { grinding }\end{array}$} & $\begin{array}{l}\text { 100Cr6 } \\
\text { steel }^{(1)}\end{array}$ & 1.12 & 20.23 & 496.93 & 34.67 & 1.52 & 26.36 & 1869.02 & 79.92 \\
\hline & $\begin{array}{c}\text { Titanium } \\
\text { Grade } 2^{\circledR} \text { alloy }^{(2)}\end{array}$ & 1.15 & 18.93 & 492.03 & 31.21 & 1.52 & 24.21 & 1721.34 & 76.03 \\
\hline \multirow{2}{*}{ Traverse grinding } & $\begin{array}{l}\text { 100Cr6 } \\
\text { steel }^{(1)}\end{array}$ & 1.20 & 19.15 & 501.24 & 36.69 & 1.57 & 24.98 & 1773.23 & 82.11 \\
\hline & $\begin{array}{c}\text { Titanium } \\
\text { Grade } 2^{\circledR} \text { alloy }^{(2)}\end{array}$ & 1.17 & 18.65 & 488.48 & 33.31 & 1.61 & 27.24 & 1987.91 & 86.98 \\
\hline
\end{tabular}

(iii) The dimensional range of spherical melted chips generally varies between 0.3 and $30 \mu \mathrm{m}$.

(iv) Spherical melted chips of various sizes are formed as a single chip (Figure 2(a)) or as a cluster (Figure 5(c)) containing from a few to several dozen chips (the clusters analyzed in this paper contained from 10 to 150 objects).

(v) The average dimension of spherical melted chips occurring singly (regardless of the kinematic variety of internal cylindrical grinding process and workpiece material) was $S_{\text {max. }}=19.4 \mu \mathrm{m}$ for near-spherical chips and $S_{\text {max. }}=25.59 \mu \mathrm{m}$ for semispherical chips. The values of this same parameter calculated for clusters were lower and amounted: $S_{\max }=5.42 \mu \mathrm{m}$ for near-spherical chips and $S_{\max }=8.21 \mu \mathrm{m}$ for semispherical chips.

(vi) Spherical melted chips are formed generally around other types of chips. They may be localized in a surface of abrasive grains (Figure $2(\mathrm{a})$ ) or in free intergranular spaces (Figure 6(d)).

(vii) The carried out grinding tests revealed that melted spherical chips occur regardless of the kinematic variation of the internal cylindrical grinding process. It follows that the main factor determining the creation of this kind of chip is a considerable temperature increase caused by a long grinding zone, characteristic of internal cylindrical grinding processes.

The presence of spherical chips shows difficult conditions of the grinding process and results principally from the high temperature in the contact zone between active vertices of the abrasive grains and machined surface. Effect of heat generated in the grinding process is particularly damaging in the case of the machining of titanium alloys, which are strengthening due to elevated temperatures considerably hampering the removal of material. Therefore, the analysis of the number and size of spherical chips gives the opportunity to conclude about the conditions in the grinding zone in order to optimize them for specific grinding operations. The formation of spherical chips does not directly affect the quality of the machined surface because they are formed by oxidation in an oxygen atmosphere outside the machining zone. However, their existence may be related to the increased intensity of the grinding wheel wear because it indicates unsatisfactory cooling of the grinding zone. With the increase of temperature of the process, strength properties of the abrasive grains and the bond bridges are reduced, which causes their premature wear.

\section{Competing Interests}

The authors declare that they have no competing interests.

\section{Acknowledgments}

The authors wish to thank Mr. Ryszard Gritzman and Zbigniew Kukliński, MSc, BSc, from the Laboratory of Electron Microscopy and the Structural Research Central Laboratory of the Institute of Mechatronics, Nanotechnology and Vacuum Technique at Koszalin University of Technology (Koszalin, Poland), for the acquisition of SEM micrographs by the JSM-5500 LV.

\section{References}

[1] U. A. Dabade and S. S. Joshi, "Analysis of chip formation mechanism in machining of $\mathrm{Al} / \mathrm{SiCp}$ metal matrix composites," Journal of Materials Processing Technology, vol. 209, no. 10, pp. 4704-4710, 2009.

[2] A. Ebrahimi and M. M. Moshksar, "Evaluation of machinability in turning of microalloyed and quenched-tempered steels: tool 
wear, statistical analysis, chip morphology," Journal of Materials Processing Technology, vol. 209, no. 2, pp. 910-921, 2009.

[3] P. Twardowski, S. Legutko, G. M. Królczyk, and S. Hloch, "Investigation of wear and tool life of coated carbide and cubic boron nitride cutting tools in high speed milling," Advances in Mechanical Engineering, vol. 7, no. 6, pp. 1-9, 2015.

[4] S. Zhang and Y. B. Guo, "An experimental and analytical analysis on chip morphology, phase transformation, oxidation, and their relationships in finish hard milling," International Journal of Machine Tools and Manufacture, vol. 49, no. 11, pp. 805-813, 2009.

[5] F. B. de Oliveira, A. R. Rodrigues, R. T. Coelho, and A. F. de Souza, "Size effect and minimum chip thickness in micromilling," International Journal of Machine Tools and Manufacture, vol. 89, pp. 39-54, 2015.

[6] R. Li, L. Riester, T. R. Watkins, P. J. Blau, and A. J. Shih, "Metallurgical analysis and nanoindentation characterization of Ti-6Al-4V workpiece and chips in high-throughput drilling," Materials Science and Engineering A, vol. 472, no. 1-2, pp. 115124, 2008.

[7] F. Ke, J. Ni, and D. A. Stephenson, "Continuous chip formation in drilling," International Journal of Machine Tools and Manufacture, vol. 45, no. 15, pp. 1652-1658, 2005.

[8] D. Zhu, S. Yan, and B. Li, "Single-grit modeling and simulation of crack initiation and propagation in SiC grinding using maximum undeformed chip thickness," Computational Materials Science, vol. 92, pp. 13-21, 2014.

[9] D. Setti, M. K. Sinha, S. Ghosh, and P. Venkateswara Rao, "Performance evaluation of Ti-6Al-4V grinding using chip formation and coefficient of friction under the influence of nanofluids," International Journal of Machine Tools and Manufacture, vol. 88, pp. 237-248, 2015.

[10] P.-L. Tso, "An investigation of chip types in grinding," Journal of Materials Processing Technology, vol. 53, no. 3-4, pp. 521-532, 1995.

[11] Y. C. Wong and E. D. Doyle, "Implications of high strain deformation in grinding," Wear, vol. 233-235, pp. 395-401, 1999.

[12] S. Malkin, "Negative rake cutting to simulate chip formation in grinding," CIRP Annals-Manufacturing Technology, vol. 28, no. 1, pp. 209-212, 1979.

[13] E. D. Doyle and S. K. Dean, "An insight into grinding from materials viewpoint," CIRP Annals-Manufacturing Technology, vol. 29, no. 2, pp. 571-575, 1980.

[14] H. Letner, "Modern perspective of grinding process," Grinding and Finishing, no. 1, p. 36, 1995.

[15] D. J. Badger, "Grinding: a pictorial odyssey; An examination of the grinding process through the lens of an electron microscope," Cutting Tool Engineering Magazine, vol. 61, no. 2, pp. 4449, 2009.

[16] J. Badger, "Grinding: a pictorial odyssey, part II," Cutting Tool Engineering, vol. 61, no. 12, pp. 48-52, 2009.

[17] L. Lu, T. N. Farris, and S. Chandrasekar, "Sliding microindentation wear particles: spheres in grinding swarf," Tribology Series, vol. 21, pp. 257-263, 1992.

[18] G. Su and Z. Liu, "Experimental analysis on spherical chips in high-speed machining of hardened AerMet100," Materials Science Forum, vol. 723, pp. 67-71, 2012.

[19] W. Kapłonek and K. Nadolny, "Assessment of the grinding wheel active surface condition using SEM and image analysis techniques," Journal of the Brazilian Society of Mechanical Sciences and Engineering, vol. 35, no. 3, pp. 207-215, 2013.
[20] K. Nadolny and W. Kapłonek, "SEM-based morphological analysis of the new generation aion-based abrasive grains (Abral ${ }^{\circledR}$ ) with reference to $\mathrm{Al}_{2} \mathrm{O}_{3} / \mathrm{SiC} / \mathrm{cBN}$ abrasives," Acta Microscopica, vol. 24, no. 1, pp. 64-78, 2015. 

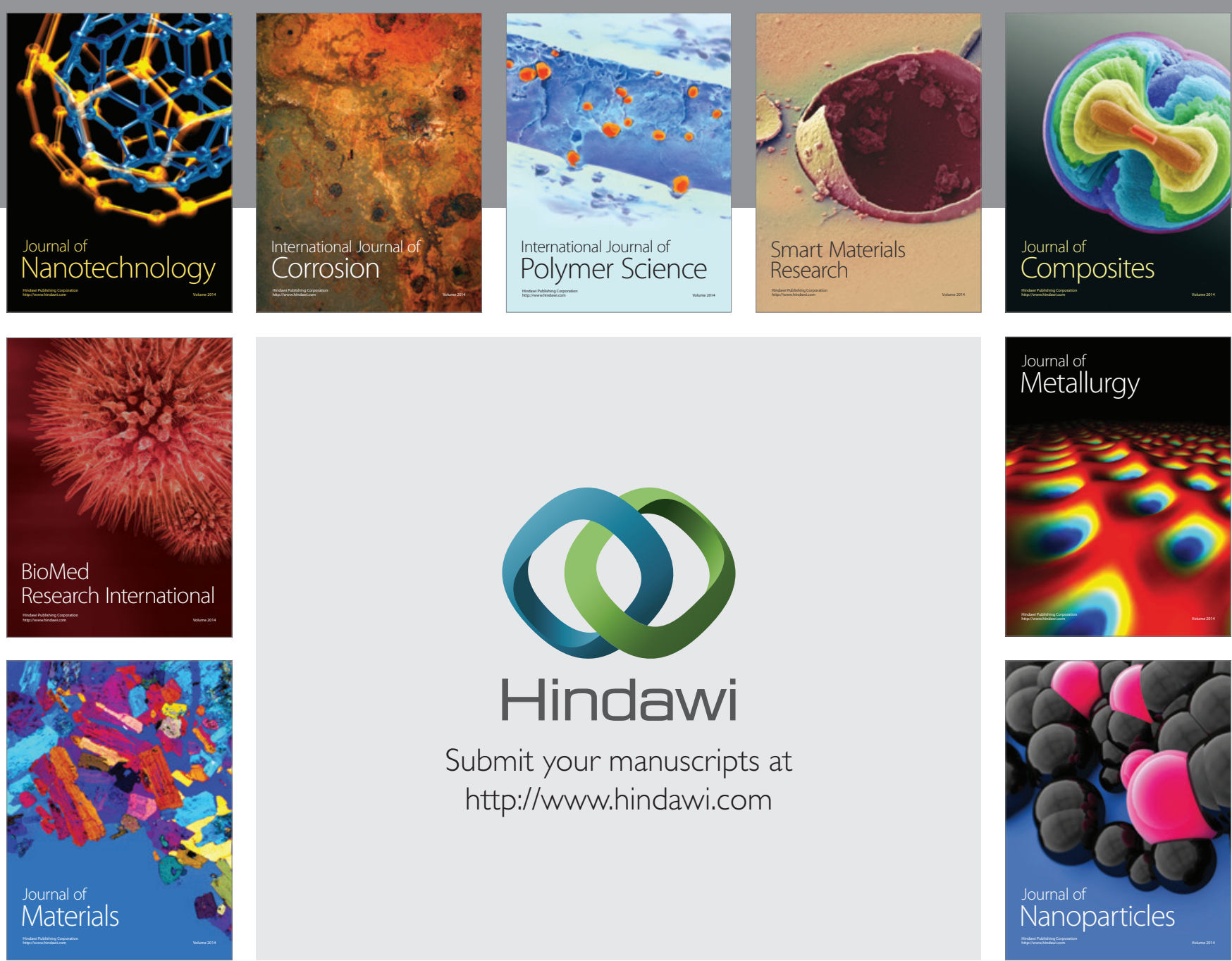

\section{Hindawi}

Submit your manuscripts at

http://www.hindawi.com

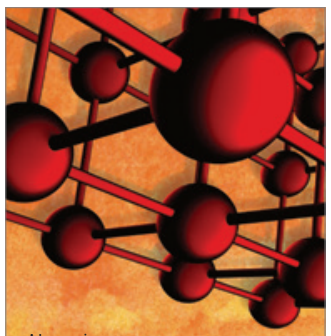

Materials Science and Engineering
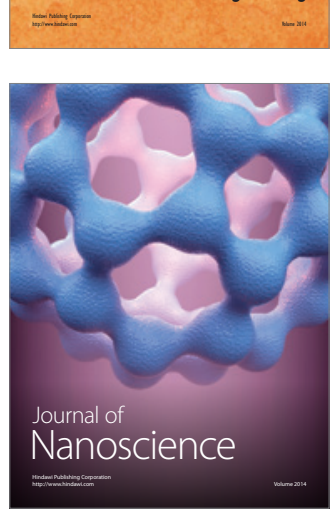
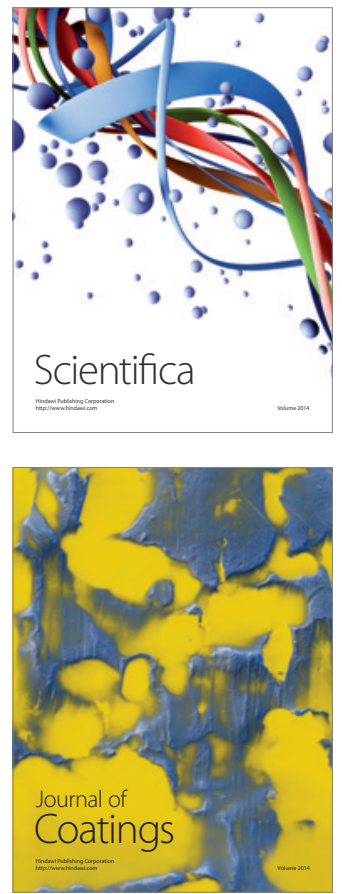
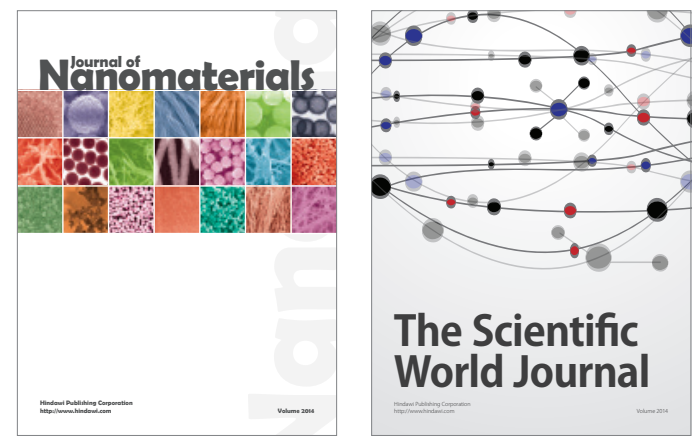

The Scientific World Journal
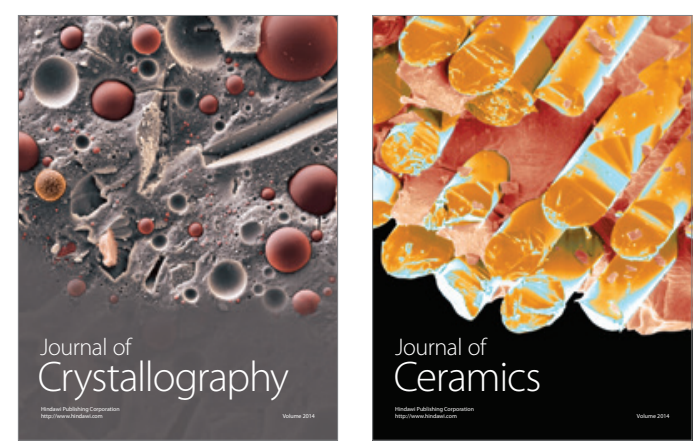
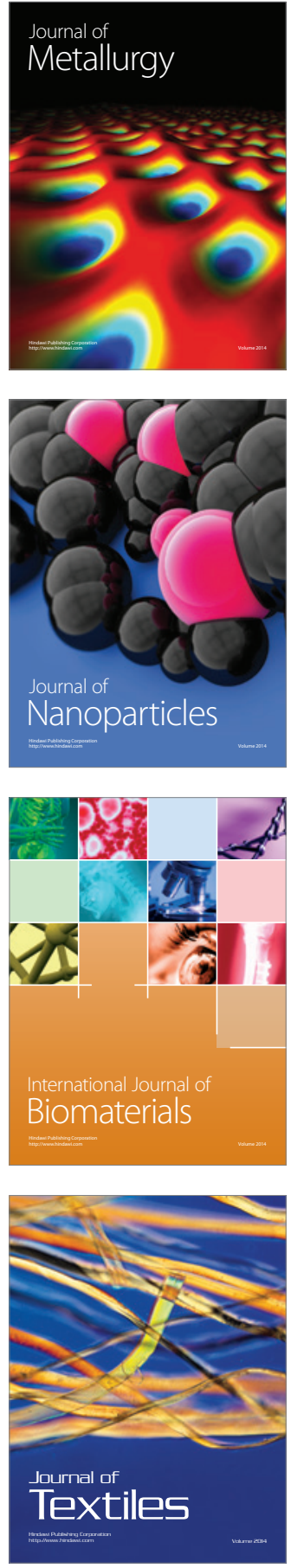